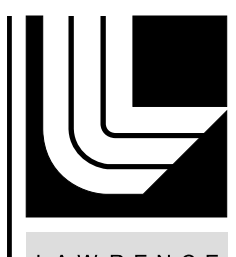

LAW RENCE LIVERMORE N A TION A L LABORATORY
UCRL-JRNL-222395

Fragmentation in Biaxial Tension

Geoffrey H. Campbell, Gregory C. Archbold, Omar A. Hurricane, Paul L. Miller

June 26, 2006

Acta Materialia 
This document was prepared as an account of work sponsored by an agency of the United States Government. Neither the United States Government nor the University of California nor any of their employees, makes any warranty, express or implied, or assumes any legal liability or responsibility for the accuracy, completeness, or usefulness of any information, apparatus, product, or process disclosed, or represents that its use would not infringe privately owned rights. Reference herein to any specific commercial product, process, or service by trade name, trademark, manufacturer, or otherwise, does not necessarily constitute or imply its endorsement, recommendation, or favoring by the United States Government or the University of California. The views and opinions of authors expressed herein do not necessarily state or reflect those of the United States Government or the University of California, and shall not be used for advertising or product endorsement purposes. 


\section{Fragmentation in Biaxial Tension}

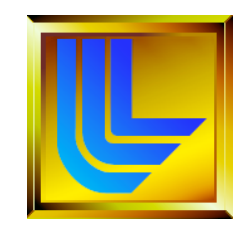

By

Geoffrey H. Campbell, Gregory C. Archbold, Omar A. Hurricane, and Paul L. Miller Lawrence Livermore National Laboratory, Livermore, CA 94550

Keywords: Stainless steel, fracture, dynamic phenomena, deformation structure, fragmentation

Unclassified

ADC Review by: Omar A. Hurricane

Title: Program Element Leader

Date: 22 June 2006

Guide: COK-2001-600 Topics: 10-502, 10-506.1, 11-101

Guidance date: September 2001

Guide: TCG-WM-1

Topics: 1102, 1103

Guidance Date: 16 October 1995 


\title{
UNCLASSIFIED
}

\begin{abstract}
We have carried out an experiment that places a ductile stainless steel in a state of biaxial tension at a high rate of strain. The loading of the ductile metal spherical cap is performed by the detonation of a high explosive layer with a conforming geometry to expand the metal radially outwards. Simulations of the loading and expansion of the metal predict strain rates that compare well with experimental observations. A high percentage of the HE loaded material was recovered through a soft capture process and characterization of the recovered fragments provided high quality data, including uniform strain prior to failure and fragment size. These data were used with a modified fragmentation model to determine a fragmentation energy.
\end{abstract}




\section{UNCLASSIFIED}

\section{Introduction}

Fragmentation is a mode of failure observed in materials undergoing dynamic deformation. Under dynamic conditions, the kinetic energy of the deforming body is significant compared to other potential energy sources for the driving of failure processes. Additionally, in the fragmentation process, relief waves that are formed by the creation of a failure surface have time to propagate only a limited distance, allowing the nucleation and growth of other failure surfaces beyond this distance. The result of multiple failure sites is that the body breaks up into many pieces (fragments).

Previous experimental investigations have mostly been performed in the expanding cylinder geometry (see for example [1-3]), however other experimental geometries have provided useful results as well, including the expanding ring [4-6], plate impact [7], and expanding sphere $[8,9]$.

Analytical modeling of the fragmentation process has developed along two lines. The first approach was initiated by Taylor [10] for high explosives (HE) loading of a cylindrical geometry, which starts from the premise that the interior surface of the cylinder is against high pressure detonation products that cause it to accelerate. The acceleration leads to a region of the cylinder near the inside wall that is under a compressive hoop stress while the region outside is under tensile hoop stresses. The failure surfaces will evolve only in regions of tensile hoop stress and through thickness failure will be determined by the reduction of the internal driving pressure such that the tensile hoop stresses become present throughout the cross section. These methods have been applied to understand the failure mode of steel tubes [11] and have been extended to the case of spherical geometry [12]. 


\section{UNCLASSIFIED}

The second line of analytical modeling has been based on the original work of Mott [13], which is driven by inertial effects. The approach uses an energy balance between that available to perform work in the form of kinetic energy and that dissipated by the process of forming a failure surface [14]. Subsequently, the stored elastic strain energy was also considered $[15,16]$. The work of Mott emphasized the statistical nature of the fragmentation process and recent work has expanded the connection between the statistical and inertial aspects of fragmentation [17]. The consideration of linear loading waves has yielded models that are applicable to brittle materials $[18,19]$. Plastically yielding metals provide a much less tractable problem for analysis, however one striking result has shown that release waves (Mott waves) created at failure surfaces propagate in a diffusional manner [20].

Simulations of fragmentation with numerical techniques have also been developed. Recent work has focused on cohesive zone models [21-23], with their attendant mesh dependence.

The goal of the current work is the generation of statistically significant data on the fragmentation of a plastically deforming metal under biaxial straining conditions. We measure the uniform plastic strain prior to fragmentation and the fragment sizes. Both of these quantities exist as distributions. Simulations are used to predict a strain rate for the metal and these are compared to surface velocity measurements of the expanding part. Combining the strain rate and strain to failure gives a time of failure that is compared to the high-speed optical images of the fragmentation process that also identifies a time. Finally, we use a slightly modified version of the Glenn and Chudnovsky [15] model to determine a fragmentation energy. 


\section{UNCLASSIFIED}

\section{Experiment}

\subsection{Material}

The experiment investigated the fragmentation behavior of $304 \mathrm{~L}$ stainless steel (SS). It was procured in the form of rolled plate, $38 \mathrm{~mm}(1.5 \mathrm{in})$ thick. The spherical cap part used in the experiment was machined from this plate with no additional forming steps and using stress relief anneals $\left(400^{\circ} \mathrm{C}\right.$ for $\left.1 \mathrm{~h}\right)$ only between machining steps. The stress relief anneals are required to meet the stringent specification of thickness required to make the thickness change measurements on the recovered fragments. The grain size of the SS was qualitatively assessed as approximately $100 \mu \mathrm{m}$, with a rather broad distribution about the mean.

\subsection{Geometry}

The geometry of the fragmentation experiment is shown in Figure 1. The SS subjected to the fragmentation study is present as the outer layer in the assembly. Its thickness is 3 $\mathrm{mm}$ and it is in the form of a spherical cap with radius of curvature $200 \mathrm{~mm}$. When viewed face-on, the diameter of the cap is $184 \mathrm{~mm}$, subtending a conical semi-angle of $27.4^{\circ}$. The perimeter of the cap has a lip that mates with a steel ring used to simplify alignment during assembly (not shown in Fig.1). A conforming layer, $20 \mathrm{~mm}$ thick, of HE backs the spherical SS cap. The HE is $95.5 \%$ by weight octahydro- $1,3,5,7-$ tetranitro - 1, 3, 5, 7 - tetrazocine (HMX) with a polymer binder. The total amount of HE was measured as $912.5 \mathrm{~g}$. It is detonated in the center of the concave side with an RP-2 (RISI, Reynolds Industries Inc.) exploding bridge wire detonator.

\subsection{Recovery method}

The experiment is hung from a support structure made of a polyurethane foam board supported on an aluminum alloy framework. The experiment is faced downwards into the 


\section{UNCLASSIFIED}

recovery system (see Figure 2). It is stood off from the recovery system by approximately $1 \mathrm{~m}$. The first layers of the recovery system are made of polyurethane foam of graded density. The first $600 \mathrm{~mm}$ are $80 \mathrm{~kg} / \mathrm{m}^{3}$ ( $5 \mathrm{lb}$./cu.ft.) foam, followed by $200 \mathrm{~mm}$ of 320 $\mathrm{kg} / \mathrm{m}^{3}$ (20 lb./cu.ft.) foam. These foam layers are floated on a tank of water $\left(1000 \mathrm{~kg} / \mathrm{m}^{3}\right)$ with depth of approximately $1 \mathrm{~m}$. The diameter of the recovery system (approximately 2 m) and stand off distance were chosen to intersect the entire debris cone determined by the $27.4^{\circ}$ conical semi-angle of the spherical cap of the experiment. The recovery scheme is designed to prevent secondary damage to the fragments during their deceleration. The goal of the recovery system is to have all strain in the recovered fragments arise from the HE loading alone.

After the experiment is fired, the foam debris is removed from floating on the top of the water and the water is drained from the tank. The fragments are then recovered from the bottom of the tank.

\subsection{Velocimetry}

An optical heterodyne technique was used to measure the velocity of the free surface of the SS cap. Both the laser light illumination and return signal were brought to the experiment through a fiber optic. The final optic is a lens approximately $10 \mathrm{~mm}$ in diameter with a stand off from the surface of the experiment of $200 \mathrm{~mm}$. It is held in place by a foam bracket. It focuses the probe onto a spot on the specimen surface that is half way between the pole and edge of the spherical cap. The measurement spot size on the specimen is approximately $1 \mathrm{~mm}$. A ball rolling technique is used to roughen that spot on the surface in order to produce diffusely scattered light. We have found no indication that this surface treatment affects the dynamic properties of the specimen. Also, the final 


\section{UNCLASSIFIED}

optics assembly with bracket is mostly plastic with a small amount of glass, so that, even though it is in the path of the fragments, it does not appear to have a noticeable affect on the character of the recovered fragments. It is too small to produce secondary damage to the fragments that would be noticeable in the statistical analysis of the measurements taken on those fragments.

\subsection{Optics}

Two high-speed rotating mirror cameras were used to record optical images of the dynamically expanding SS cap. Timing on the optical images is set by using the coincidence of the mirror positions of the two cameras to actually start the firing sequence. At $20 \mu \mathrm{s}$ after camera coincidence, an electronic Xe flash lamp with illumination time of $65 \mu \mathrm{s}$ FWHM is fired. At $40 \mu \mathrm{s}$ after camera coincidence, the detonator on the $\mathrm{HE}$ is fired. One camera records from $50 \mu \mathrm{s}$ to $89 \mu$ s past camera coincidence with frame to frame time of $1.5 \mu \mathrm{s}$ and the other records from $84 \mu \mathrm{s}$ to 110 $\mu$ s with $1 \mu \mathrm{s}$ frame to frame time. Each camera records 26 images. It is often convenient to refer to the detonation time for comparison to the simulations, thus $40 \mu \mathrm{s}$ is subtracted from the times reported from here out to change the reference time to the detonation time. The camera times were chosen to cover the times prior to fragmentation and the pre-shot estimation of when the fragmentation process would occur. For accurate timing of the frames, a laser fiducial mark is placed on 5 frames at a set reference time after the detonator circuit load ring.

\subsection{Fragment analysis techniques}

As the SS spherical cap is dynamically expanded by the HE loading, it plastically stretches in biaxial tension while contracting in its through thickness direction. For some 


\section{UNCLASSIFIED}

period of time this plastic strain is uniform, until plastic instability appears and localization of the deformation starts to dominate followed by failure and formation of fragments. At the initiation of localization, the non-localized regions are unloaded by a relief wave and uniform straining ceases. These areas are measured for thickness in the recovered fragments. Using the log strain definition and the assumption of equi-biaxial strain, the compression strain in the through thickness direction is equally partitioned into tensile strain along two axes in plane. This strain path should be kept in mind as the strains quoted below are the tensile strains; the through thickness strains would be doubled and of the opposite sign. Likewise, for comparison with strain to failure in a tensile test, the strain numbers quoted here should be approximately doubled for a comparison based on equivalent plastic strain.

The thickness of each recovered fragment is measured at about 5 points, avoiding the occasional incipient failure site in the form of a neck, and the measurements averaged for a given fragment. The fragment is then weighed on a balance. With the thickness and weight of each fragment, an assumed disk shape is used to calculate an equivalent radius as a measure of size.

Certain fragments were excluded from these measurements. The regions around the edge of the spherical cap are subjected to a release wave propagating inwards from the free edge that halts the strain in the radial direction. The spherical cap has a lip machined around the edge. Simulations show that as the HE detonation interacts with the corner produced by this lip, it quickly breaks away the lip, creating the free edge. Thus, for a distance that increases with time, these regions have their strain path modified to be more nearly uniaxial (in the hoop direction) rather than biaxial. However, these fragments can 


\section{UNCLASSIFIED}

be identified in the population of recovered fragments. One edge of these fragments will contain the edge of the cap and two other edges will be formed parallel by failure surfaces normal to the hoop strains. These fragments are excluded from the analysis of the recovered fragments so that only regions of nearly equi-biaxial strain are considered.

Standard characterization approaches are used on the SS. The microstructure is characterized with optical microscopy of both polished and etched cross-sections of fragments and the as-received material. Deformation microstructures were also characterized with transmission electron microscopy (TEM). The fracture surfaces were characterized by scanning electron microscopy (SEM).

\section{Simulations}

\subsection{Continuum hydrodynamic code}

The experiment was designed using computer simulations with CALE, a 2D ALE (Arbitrary Lagrangian Eulerian) hydrodynamics computer program written in the "C" programming language $[24,25]$. The physics algorithms and approximations used in CALE are a combination of a wide variety of ideas and techniques developed by many different people at LLNL over the last 30 years.

Figure 3 shows the simulation set-up in CALE, where the $\mathrm{x}$-axis is the axis of rotational symmetry. The dark green is the $304 \mathrm{~L}$ stainless steel shell, and the red is the HE. The piece of stainless steel shown in light green serves both as a safety sleeve around the HE and a mounting flange which rests on the yellow foam. The detonator, with its aluminum sleeve, is visible on-axis at the back of the high explosive. The mesh is conformal in the HE and the stainless steel shell, with 96 zones through the thickness of 


\section{UNCLASSIFIED}

the $\mathrm{HE}$ and 48 through the stainless steel. The mesh is much less dense in the surrounding air.

Pre-experiment simulations were used to predict the fragment velocities, which in turn were used to adjust the foam layers of the soft capture assembly and to set the fields of focus for the high speed framing cameras. Following the experiment, the models in the simulation were adjusted to match the velocimetry data (shown later in Figure 10), and the adjusted simulations were used to determine strain rates. Figure 4 shows pressure and density contours using the post-experiment simulations.

Figure 5 shows pressure as a function of time near the pole and about half way from the pole to the edge. The strong first shock is tens of GPa, followed by a rarefaction that puts the material under tension. The reflected waves ring for several $\mu \mathrm{sec}$, after which the material settles into a state of tension that is determined by the strength model.

\subsection{HE modeling}

A conventional Jones-Wilkins-Lee (JWL) equation of state (EOS) was used to model the HE behavior. A nominal charge of $918 \mathrm{~g}$ of an HMX-based high explosive with a density of $1.85 \mathrm{~g} / \mathrm{cm}^{3}$ drives the experiment. The detonation energy is $5.5 \mathrm{~kJ} / \mathrm{g}$, which corresponds to a $1.23 \mathrm{TNT}$ equivalent. The detonation velocity is $8.83 \mathrm{~mm} / \mu \mathrm{s}$, the heat of combustion is $9.60 \mathrm{~kJ} / \mathrm{g}$, and the nominal Chapman-Jouguet pressure $\left(\mathrm{P}_{\mathrm{cj}}\right)$ is $38.1 \mathrm{GPa}$. To match the velocimetry data, the $\mathrm{P}_{\mathrm{cj}}$ in the simulation was lowered to $33.3 \mathrm{GPa}$ and the HE energy was lowered by $6.5 \%$.

The HE burn model in CALE is a simple geometric Huygens lighting model. The model is lit in a disk region on axis, with the radius of the RP2 exploding bridgewire detonator used in the experiment. The detonation proceeds isotropically within the HE 


\section{UNCLASSIFIED}

material region at the programmed detonation speed. The snapshots in Figure 4 illustrate the propagation of the burn.

\subsection{EOS and strength model for stainless steel}

The equation of state used in the simulations was of the linear polynomial form, with parameters taken from [26]. To match the velocimetry data, the maximum tensile hydrostatic pressure allowed was $3 \mathrm{GPa}$ and the minimum compression $\left(\eta=\rho / \rho_{\mathrm{o}}\right)$ was 0.9 .

Simulations incorporated elastic-plastic effects with a Steinberg-Guinan strength model [27]; the shear modulus and yield strength are calculated as functions of pressure, temperature, and equivalent plastic strain. Each cycle the work-hardened yield strength is found - but not allowed to exceed $2.5 \mathrm{GPa}$ - then softened as a function of pressure and thermal and melt effects. The parameters for the strength model were taken from [26].

\subsection{Predicted strain rates}

In biaxial tension, the strain rate in a mass element can be related to the change of area compared to the original area. The spherical geometry of the experiment allows this comparison simply in terms of the time rate of change of the radius of the shell as measured from the static center of curvature. Figure 6 shows plots of $\Delta \mathrm{A} / \mathrm{A}_{\mathrm{o}}$ near the pole and about half way to the edge. The slopes of these curves are related to the strain rate.

Information like that in Figure 6 was extracted from the post-experiment best-fit simulations. The strain rate near the pole is $8.78 \times 10^{3} \mathrm{~s}^{-1}$, and varies from $8.76 \times 10^{3} \mathrm{~s}^{-1}$ to $9.33 \times 10^{3} \mathrm{~s}^{-1}$ with an average of $9.11 \times 10^{3} \mathrm{~s}^{-1}$. The average is weighted by the square of the distance from the pole of the tracer, accounting for the more mass at larger radii. 


\section{UNCLASSIFIED}

\section{Failure modeling}

Previous analyses of fragmentation have identified two sources of energy available to drive the fracture process. The first was postulated by Grady [14] to be the kinetic energy of a fragment relative to its center of mass. Later, Glenn and Chudnovsky [15] added the stored elastic strain energy of the fragment to the formulation. The premise of both analyses is that the stored energy in these two energy sources is available to work against the dissipative effects of the fracture surface formation. So we can write the total energy, $\mathrm{W}_{\text {tot}}$, on a per fragment basis as

$$
W_{t o t}=W_{k}+W_{e}-W_{f}
$$

where $W_{k}$ is the available kinetic energy of the fragment, $W_{e}$ is the elastic strain energy of the fragment, and $\mathrm{W}_{\mathrm{f}}$ is the energy required to form the fracture surfaces of the fragment. The negative sign in front of $\mathrm{W}_{\mathrm{f}}$ indicates that it is dissipative. We idealize the geometry of the experiment to be an infinite plate of uniform thickness expanding under an equal biaxial straining condition and fragmenting into circular disks with dimensions shown in Figure 7. We realize that the incipient disk is expanding in radius while it is contracting in height and write the kinetic energy of a cylindrical shell of mass, $d m$, within the circular disk as comprising of two parts:

$$
d W_{k}=\frac{1}{2} \dot{r}^{2} d m+\frac{1}{2} \dot{h}^{2} d m
$$

where

$$
d m=2 \pi \rho h r d r
$$

and

$$
\dot{r}=-\dot{\varepsilon} r
$$

and 


\section{UNCLASSIFIED}

$$
\dot{h}=2 \dot{\varepsilon} h
$$

where the strain rate is taken to be that in the plane of the plate. The kinetic energy about the center of mass is available for creating the fracture surfaces and is given by the integration of $\mathrm{dW}_{\mathrm{k}}$ out to the disk radius, $a$,

$$
W_{k}=\int_{0}^{a} d W_{k}=\frac{\pi}{4} \rho h \dot{\varepsilon}^{2} a^{4}+2 \pi h^{3} \rho a^{2} \dot{\varepsilon}^{2} .
$$

The total stored elastic strain energy per fragment, $\mathrm{W}_{\mathrm{e}}$, is given by:

$$
W_{e}=\frac{\sigma_{f}^{2}}{2 E^{*}} \pi a^{2} h
$$

where $\sigma_{f}$ is the flow stress and $E^{*}$ is the modulus appropriate for biaxial loading:

$$
E^{*}=\frac{E}{1-v}
$$

with $E$ being the Young's modulus and $v$ the Poisson's ratio. A schematic illustration of the origin of this strain energy is shown in Figure 8. It is interesting to note that the modulus is not a function of plastic strain. It is purely determined through considerations of interatomic interactions. However, if damage is present, such as in the form of voids or microcracks, then the effective modulus can be decreased.

Both Grady and Glenn and Chudnovsky formulated their relations in terms of the critical stress intensity factor, $\mathrm{K}_{\mathrm{IC}}$, which is unlikely to be applicable in the current case of a generally yielding metal. The fracture energy, $\Gamma_{f}$, is more appropriate and invoking the spirit of Griffith [28] we can write

$$
\Gamma_{f}=2 \gamma
$$

where $\gamma$ is the fracture surface formation energy per unit area. We can then write the total fracture energy dissipated per fragment as:

$$
W_{f}=\Gamma_{f} \pi a h .
$$




\section{UNCLASSIFIED}

We can then write the total energy function for a fragment by summing the three contributions:

$$
W_{t o t}=\frac{\pi}{4} \rho h \dot{\varepsilon}^{2} a^{4}+2 \pi \rho h^{3} \dot{\varepsilon}^{2} a^{2}+\frac{\sigma_{f}^{2}}{2 E^{*}} \pi h a^{2}-\Gamma_{f} \pi h a .
$$

We then postulate that the change in this function with respect to fragment size gives rise to work conjugate forces that must be in mechanical equilibrium when the fracture event occurs that creates the fragment, so that we may write:

$$
\frac{\partial W_{t o t}}{\partial a}=0=\pi \rho h \dot{\varepsilon}^{2} a^{3}+4 \pi \rho h^{3} \dot{\varepsilon}^{2} a+\frac{\sigma_{f}^{2}}{E^{*}} \pi h a-\Gamma_{f} \pi h .
$$

Finally, rearrangement gives:

$$
\Gamma_{f}=\rho \dot{\varepsilon}^{2}\left(a^{3}+4 h^{2} a\right)+\frac{\sigma_{f}^{2}}{E^{*}} a
$$

in which the fracture energy is expressed as the sum of two terms, the first arising from the kinetic energy contribution and the second from the stored strain energy.

\section{Results}

\subsection{Optical framing camera images}

The optical framing camera record of the experiment is shown in Figure 9, with times of the images noted in the caption. The first image shows the flash of the detonating HE at the edge of the SS cap, emphasizing that detonator function time and the transiting of the HE detonation wave from the poll to the edge require about $10 \mu \mathrm{s}$. Visible in the second image is the cloud of HE detonation products escaping from the edge of the SS cap. A small cloud is also noted at the center of the cap, caused by the location of the detonator under this point. It is surmised that the detonator creates a jet under its position that punches through the SS layer. This localized breach of the material evolves with time into a larger hole, letting more HE detonation products through, as seen in the subsequent 


\section{UNCLASSIFIED}

frames. In the third and forth frames, the beginnings of the failure process can be seen. Surface irregularities due to neck formation are becoming visible in the reflected light from the surface. In the final two frames, cracks have begun to penetrate through the thickness of the part, which is shown by the emergence of the HE detonation products through to the surface. The last two frames also show the collision of the moving SS surface traveling in excess of $1 \mathrm{~km} / \mathrm{s}$ with the foam bracket holding the velocimetry probe. A bright flash in frame 5 at the point of collision is due to ionization of the foam.

\subsection{Velocimetry}

The measured velocity of the surface of the spherical cap is shown in Figure 10. The jump-off velocity at shock breakout at the surface is $1.1 \mathrm{~km} / \mathrm{s}$. It shows three pull back features (periods of deceleration) after shock breakout during the acceleration phase to a final steady state velocity of $1.8 \mathrm{~km} / \mathrm{s}$. These pull back features are interpreted as ringing in the metal shell as the shock wave reverberates between the surfaces. A compressive wave will reflect as a tensile wave at a free surface, causing the deceleration of the surface. These reflected tensile waves are closely linked to the phenomenon of spall [29]. The reflected tensile waves can lead to damage in the metal in the form of voids that nucleate and grow. The extent of the damage is sensitively dependent on the duration of the tensile wave experienced by any part of the metal, which in turn is determined by the thickness of the metal. In the worst case, the metal can split at internal surface if the voids grow to the point of linking. However, as related in section 5.5.1, the $3 \mathrm{~mm}$ thick section of the current configuration giving the brief tensile pullbacks seen in Figure 10 is insufficient to cause any observable damage to the SS. 


\section{UNCLASSIFIED}

Also shown on Figure 10 are the results of the best-fit simulation. These data were the most constraining on the modeling. The simulation producing the good match in Figure 10 was used to determine the strain rates in the experiment, as discussed in section 3.6.

\subsection{Uniform strain prior to failure}

The number of fragments recovered was 100 from the central region, with an additional 43 originating from the edge of the spherical cap. The total weight of fragments constitutes $60 \%$ of the cap, excluding the rim, which breaks away cleanly and has a trajectory that takes it away from the recovery system. The lost material is likely caught in the polyurethane foam layers and could be a source of systematic bias to the data if it filtered out a particular size of fragment. The fragments are recovered in a very clean condition, with shiny metallic surfaces showing no corrosion. Very little difference is observed between the outer surface of the fragments and the inner surface that contacts the HE.

The original thickness of the spherical cap was measured to be $2.995 \pm 0.005 \mathrm{~mm}$ across its entire surface. Of the 100 recovered fragments from the central region, 97 of them were suitable for thickness measurements. The average measured thickness for each fragment was used to calculate the strain for that fragment. The histogram of strains measured for the recovered fragments is shown in Figure 11. The mean for this distribution is 0.38 tensile biaxial strain (a compressive strain of 0.76 through thickness). The tail at lower strain levels is most likely due to the stress relief occurring around the premature failure area at the center of the cap seen in the high speed optical record of the shot. 


\section{UNCLASSIFIED}

\subsection{Fragment sizes}

Each fragment is individually measured for thickness and weight. These measurements are used to calculate a size of each fragment based on an assumed shape of a circular disk. The histogram of radii of the calculated disk sizes (referred to here as an equivalent radius) is shown in Figure 12. The fragment size is often the quantity predicted by analytical models of the fragmentation process.

\subsection{Metallography}

\subsubsection{Optical}

Recovered fragments were investigated in cross section with optical metallography. An example of a fragment cross-sectional profile is shown in Figure 13. This section through an entire fragment reveals that the thickness varies somewhat, suggesting that diffuse necks form during the biaxial stretching of the metal. The necks compete as failure sites, but the final failure occurs by crack formation and propagation at an inclined angle through thickness. This crack formation leads to the chisel shaped ends of the fragment in the figure. Further insight is gained through the examination of higher magnification images from an incipient failure region, shown in Figure 14. The fragment imaged in Figure 14 had an incipient failure surface that stopped mid-way through the fragment. The cross-sectioning saw cut was taken through the tip of the crack that was forming the failure surfaces. The images are of the two sides of the saw cut. On one side the fracture is seen to have formed two pieces while on the other side only a strain localization feature is seen that is acting as a precursor to the failure. 


\section{UNCLASSIFIED}

\subsubsection{TEM}

Examination of the as-received SS in the TEM reveals a well-annealed microstructure with a low dislocation density. An example of the microstructure is shown in Figure 15. Annealing twins were commonly observed, as well.

Examination of the $\mathrm{SS}$ after loading by $\mathrm{HE}$ reveals a significantly different microstructure. A qualitative examination of the as-received SS with a permanent magnet revealed no discernible magnetism, however the recovered fragments were distinctly magnetic. The appearance of magnetism indicates a change in crystal structure of the material. Investigation with the TEM showed this change. Figure 16 shows the change in microstructure experienced by the material as a result of its loading history. Strain induced martensites were observed to permeate the microstructure and account for the change in magnetic properties.

\subsection{SEM fractography}

The fracture surfaces were found to be completely ductile dimple in nature. A typical SEM fractograph is shown in Figure 17. The dimples have been elongated due to the mixed mode loading on the inclined fracture plane (modes I and III). No areas of brittle or cleavage fracture were ever observed.

\section{Discussion}

\subsection{Uniform strain prior to failure versus necking}

The cross sectional metallographs reveal inhomogeneous thinning of the shell as it expands. Broad, diffuse necks appear to form and we presume compete as failure sites due to the increased stresses experienced within a neck region. However, the necks do not evolve completely into failure sites through ductile rupture by pulling down to a knife- 


\section{UNCLASSIFIED}

edge shaped failure surface. Instead what happens is that a crack forms and propagates laterally, which is revealed by Figure 14. The crack is inclined through thickness, leading to a chisel shaped failure surface. In Figure 14 a region of localized shear deformation is seen as the precursor to crack propagation. This deformation is localized near the propagating crack tip, as evidenced by the lack of these localized shear deformation features observed elsewhere in the recovered fragments. A localized crack tip plastic zone suggests that the fracture mechanics based approach taken in the modeling of fragmentation is a reasonable description of the failure process.

\subsection{Failure evolution}

The investigation of the fracture surfaces around the edges of the fragments reveals only ductile failure. The fracture surfaces were only comprised of ductile dimples, no evidence for cleavage or brittle crack propagation was ever observed. One of the assumptions implicit in the fragmentation model presented here and many of the others in the literature is that the failure event is instantaneous. The failure process observed in the present experiment is far from instantaneous in that it involves strain localization, void nucleation and growth, and finally void coalescence to cause failure.

The optical framing camera images show in the last image for which the data were acquired that through cracks exist at very few places on the shell. These locations are revealed by the penetration of $\mathrm{HE}$ detonation products through the cracks to the side being observed and become visible as clouds of smoke. Cracks propagate from these first sites, requiring many microseconds to fully evolve. 


\section{UNCLASSIFIED}

\subsection{Fragment size and failure energy}

The measurements made on the recovered fragments allow a value to be assigned to each of the quantities on the right hand side of equation 12. In this way, a quantitative assessment of the fracture energy can be made. The quantities used are shown in Table I. The strain rate was determined from the velocimetry data and the assumed shape of a self-similar spherical section expanding along radial trajectories. This assumption is slightly incorrect, but the approximation compares well with a simulated strain rate of $9.11 \times 10^{3} \mathrm{~s}^{-1}$, which should be a more accurate measure provided that the equation of state of the 304L SS is known with sufficient accuracy. The density, Poisson ratio and modulus are handbook values. The fragment thickness and equivalent radius are the average values of the populations shown in Figures 11 and 12. The flow stress used is slightly higher than usual for this material. A typical handbook value for the ultimate tensile stress for 304L SS is approximately $600 \mathrm{MPa}$. However, the microstructure observed in the recovered fragments, especially the TEM micrograph in Figure 16, shows significant amounts of strain-induced martensites forming. The formation of this phase is aided by the high strain rates and extensive plastic deformation experienced by the metal. This microstructure resembles what one would expect from the deformation of a metastable austenitic SS, such as $301 \mathrm{SS}$. The ultimate tensile stress for a $301 \mathrm{SS}$ is higher than for a $304 \mathrm{SS}$, approximately $800 \mathrm{MPa}$. This value was used in the calculation of the fracture energy for the fragment formation. The calculated fracture energy of $280 \mathrm{~kJ} / \mathrm{m}^{2}$ is not unreasonable considering the high levels of ductility observed in the material. 


\section{UNCLASSIFIED}

\section{Conclusions}

We have carried out an experiment that places a ductile stainless steel in a state of biaxial tension at a high rate of strain. The loading of the ductile metal spherical cap is performed by the detonation of a high explosive layer with a conforming geometry to expand the metal radially outwards. Simulations of the loading and expansion of the metal predict strain path and stress that compare well with experimental observations. A high percentage of the HE loaded material was recovered through a soft capture process and characterization of the recovered fragments provided high quality data, including uniform strain prior to failure and fragment size. These data were used with a modified fragmentation model to determine a fragmentation energy.

\section{Acknowledgements}

The original concepts for this experimental approach were explored by Scott Wilks and T. Scott Carman. We thank Bryan Nathan, Doug Gidding, Chris Santos, John Litsky, Pat Hurst, and Steve Holmes for design and engineering. We thank Steve Bosson for duties as ramrod. We thank Vicki Mason-Reed and Cheryl Evans for metallography, Jim Ferrera for SEM, and Rick Gross for TEM specimen preparation. We thank the crew of Bunker 851: Tom Rambur and Jim Browning (shot assembly), Ted Strand (velocimetry), Mike Wagner (framing camera), Joe Bartolick (lighting), John Elliot (console operator), Anthony Regalado (electrical engineering technician), Dave White (bunker manager). This work performed under the auspices of the U.S. Department of Energy by the University of California, Lawrence Livermore National Laboratory under Contract W7405-Eng-48. 


\section{UNCLASSIFIED}

\section{References}

[1] Taylor GI. Analysis of the explosion of a long cylindrical bomb detonated at one end. In: Batchelor GK, editor. The scientific papers of sir geoffrey ingram taylor. Cambridge, UK: Cambridge University Press, 1963. p. 277.

[2] Stronge WJ, Xiaoqing M and Lanting Z. Int J Mech Sci 1989; 31:811.

[3] Weimer RJ and Rogers HC. J Appl Phys 1979; 50:8025.

[4] Bar-on E and Ginsburg A. J Phys IV 2003; 110:525.

[5] Gourdin WH. J Appl Phys 1989; 65:411.

[6] Gourdin WH, Weinland SL and Boling RM. Rev Sci Instrum 1989; 60:427.

[7] Grady DE and Kipp ME. Int J Sol Struct 1995; 32:2779.

[8] Olive F, Nicaud A, Marilleau J and Loichot R. Rupture behaviour of metals in explosive expansion. In: Harding J, editor. Second conference on the mechanical properties of materials at high rates of strain. Oxford, UK: Institute of Physics, 1979. p. 242.

[9] Balagansky IA, Karanik YA, Agureikin VA, Vinogradov AV and Balaganski AI. Theor Appl Frac Mech 2001; 36:165.

[10] Taylor GI. The fragmentation of tubular bombs. In: Batchelor GK, editor. The scientific papers of sir geoffrey ingram taylor. Cambridge, UK: Cambridge University Press, 1963. p. 387.

[11] Hoggatt CR and Recht RF. J Appl Phys 1968; 39:1856.

[12] Al-Hassani STS and Johnson W. Int J Mech Sci 1969; 11:811.

[13] Mott NF. Proc Roy Soc A 1947; 189:300.

[14] Grady DE. J Appl Phys 1982; 53:322.

[15] Glenn LA and Chudnovsky A. J Appl Phys 1986; 59:1379.

[16] Ivanov AG, Raevskii VA and Vorontsova OS. Combustion, Explosion, and Shock Waves 1995; 31:211.

[17] Grady DE and Olsen ML. Int J Impact Eng 2003; 29:293.

[18] Shenoy VB and Kim K-S. J Mech Phys Sol 2003; 51:2023.

[19] Drugan WJ. J Mech Phys Sol 2001; 49:1181.

[20] Kipp ME and Grady DE. J Mech Phys Sol 1985; 33:399.

[21] Miller O, Freund LB and Needleman A. Int J Fracture 1999; 96:101.

[22] Zhou F, Molinari J-F and Ramesh KT. Int J Sol Struct 2005; 42:5181.

[23] Maiti S, Rangaswamy K and Geubelle PH. Acta Mater 2005; 53:823.

[24] Barton RT. Development of a multimaterial two-dimensional, arbitrary lagragianeulerian mesh computer program. In: Centrella JM, LeBlanc JM and Bowers RL, editor. Numerical astrophysics. Boston: Jones and Bartlett, 1985. p. 482.

[25] Tipton RE, Managan RA and Amala PAK. Cale users manual version 20060302, Lawrence Livermore National Laboratory, 2006.

[26] Steinberg DJ. Equation of state and strength properties of selected materials, Lawrence Livermore National Laboratory Report UCRL-MA-106439, 1991.

[27] Steinberg DJ, Cochran SG and Guinan MW. J Appl Phys 1980; 51:1498.

[28] Griffith AA. Phil Trans R Soc Lond A 1920; 221:163.

[29] Cochran S and Banner D. J Appl Phys 1977; 48:2729. 


\section{UNCLASSIFIED}

\section{Tables}

\section{Table I}

\begin{tabular}{|c|c|c|c|c|c|c|c|c|}
\hline Quantity & $\begin{array}{c}\text { Strain } \\
\text { rate }\end{array}$ & Density & $\begin{array}{c}\text { Fragment } \\
\text { thickness }\end{array}$ & $\begin{array}{c}\text { Fragment } \\
\text { radius }\end{array}$ & $\begin{array}{c}\text { Young's } \\
\text { modulus }\end{array}$ & $\begin{array}{c}\text { Poisson } \\
\text { ratio }\end{array}$ & $\begin{array}{c}\text { Flow } \\
\text { stress }\end{array}$ & $\begin{array}{c}\text { Fracture } \\
\text { energy }\end{array}$ \\
\hline Symbol & $\dot{\varepsilon}$ & $\rho$ & $h$ & $a$ & $\mathrm{E}$ & $v$ & $\sigma_{f}$ & $\Gamma_{\mathrm{f}}$ \\
\hline Units & $\mathrm{s}^{-1}$ & $\mathrm{~kg} / \mathrm{m}^{3}$ & $\mathrm{~m}$ & $\mathrm{~m}$ & $\mathrm{~Pa}$ & - & $\mathrm{Pa}$ & $\mathrm{J} / \mathrm{m}^{2}$ \\
\hline Value & $9.1 \times 10^{3}$ & $8.0 \times 10^{3}$ & $1.4 \times 10^{-3}$ & $7 \times 10^{-3}$ & $1.9 \times 10^{11}$ & 0.3 & $8 \times 10^{8}$ & $2.8 \times 10^{5}$ \\
\hline
\end{tabular}




\section{UNCLASSIFIED}

\section{Figure Captions}

\section{Figure 1}

A schematic illustration of the fragmentation experiment is shown in cross-section. There is an axis of rotational symmetry running horizontally through the center of the drawing. The 304L SS material is located in the outer shell, which has the geometry of a spherical cap.

\section{Figure 2}

A schematic illustration of the experimental setup shows the HE driven experiment from Fig. 1 at the top, pointed into the recovery tank. The layers of polyurethane foam have graded densities and float on the top of the water in the tank. After the experiment is fired, the foam is removed, the water is drained, and the fragments are gathered from the bottom of the tank. The high-speed cameras use mirrors to view the experiment on its front face.

\section{Figure 3}

The simulation set-up in CALE shown with materials represented by different colors. The stainless steel (SS) is dark green and the HE is red. The HE sleeve (light green) also serves as a mounting flange resting on the foam (yellow). The experiment is surrounded by air. The $\mathrm{x}$-axis is the axis of rotational symmetry and is also the location of detonation (Det).

\section{Figure 4}

Pressure and density contours from the CALE simulation show the evolution of the HE detonation and motion of the SS specimen. Figures (a) - (d) are plots of pressure at 2.5, 4, 7, and $12 \mu$ s after bridgewire burst, respectively. The color scale represents pressure in 


\section{UNCLASSIFIED}

units of GPa (Not the different scale for (a)). Figures (e) and (f) are plots of density at 25 and $40 \mu \mathrm{s}$, respectively. The color scale represents density in units of $\mathrm{g} / \mathrm{cc}$.

\section{Figure 5}

A plot is shown of the simulated pressure versus time history for two positions in the SS spherical cap. The first is very near, but not on, the symmetry axis or pole of the simulation. Here the shock pressure due to HE detonation reaches very nearly the CJ pressure of the explosive. At the second point, mid way from pole to edge, the shock pressure is significantly reduced due to the increased angle of incidence of the shock front with the back surface of the SS specimen.

\section{Figure 6}

A plot is shown of the growth in area expressed as a fraction versus time for two points of the simulation, near the pole and midway to the edge. These data are used to calculate the strain rate in the SS during the experiment. The parallelism of the lines indicates the homogeneity of the strain rate as a function of position on the specimen.

\section{Figure 7}

A schematic illustration of the idealized fragment geometry used in the analysis.

\section{Figure 8}

A schematic illustration of the stress vs. strain response of a ductile metal shows the stored strain energy available for crack propagation. As the metal is first loaded it deforms elastically, until it yields and flows plastically at a slowly varying level of stress that we refer to as the flow stress, $\sigma_{\mathrm{f}}$. At a certain level of strain, $\varepsilon_{\mathrm{f}}$, the material unloads by localization and failure. The material unloads elastically, following the modulus E*. The area under the elastically unloading curve is the stored strain energy available to 


\section{UNCLASSIFIED}

perform work, $\mathrm{W}_{\mathrm{e}}$. All of the work put into the system for plastic deformation is completely dissipated as heat.

\section{Figure 9}

Optical framing camera records are shown that were acquired at (a) 10.5, (b) 22.5, and (c) $48 \mu \mathrm{s}$ past detonator load ring in the top row and at times of (d) 49, (e) 60, and (f) $64 \mu \mathrm{s}$ past detonator load ring in the second row. The views of the experiment are different in the two rows because these are from two different cameras.

\section{Figure 10}

The measured surface velocity is shown as a function of time for a spot on the outer surface of the stainless steel cap that is midway between the pole and the edge. The time reference is from detonator load ring. The $4 \mu$ s delay until surface jump off reflects the time required for the detonation wave to travel from the detonator at the pole to the point being observed. The surface velocity from the CALE simulation is shown for comparison.

\section{Figure 11}

A histogram of the calculated biaxial tensile strain based on the change of thickness measured for the fragments shows the distribution of failure strains for the fragments. This population of 97 fragments has a mean of 0.38 uniform strain prior to failure. The standard deviation calculated for this distribution is 0.076 and may be used as a measure of the breadth of the distribution. 


\section{UNCLASSIFIED}

\section{Figure 12}

The histogram of equivalent radii is shown based on the measurement of fragment thickness and weight. The mean radius is $6.95 \mathrm{~mm}$. The calculated standard deviation of this population as a measure of its breadth is $2.47 \mathrm{~mm}$.

\section{Figure 13}

A cross-sectional optical metallograph is shown for a typical fragment. It has been etched, but the grain structure is not visible at this magnification. The inclined failure surfaces seen at either end of the fragment, creating a chisel shape, is observed on nearly every fragment. Note also the gentle thickness variation of the cross-section characteristic of diffuse necks; localized necks are not observed.

\section{Figure 14}

High magnification optical metallographs from either side of a saw cut that went through the tip of an arrested crack. Presumably the crack was propagating to form a new failure surface when an unloading wave caused it to stop propagating and remain as an incipient failure surface. On the unfailed side in (a), the precursor strain localization is evident in the sheared microstructural feature revealed by the etching and located between the arrows.

\section{Figure 15}

A low magnification TEM micrograph is shown of the as-received SS material that was taken under kinematical diffracting conditions. The moderately low dislocation content is seen along with evidence of some recrystallization.

\section{Figure 16}

A TEM micrograph from a recovered fragment showing the in-growth of strain induced martensite. Note also the high density of dislocations between the martensite phases. 


\section{UNCLASSIFIED}

\section{Figure 17}

An SEM fractograph of the edge of a recovered fragment is shown. The ductile dimples are elongated, indicated the mixed mode of loading during the crack propagation. 


\section{UNCLASSIFIED}

\section{Figures}

Figure 1

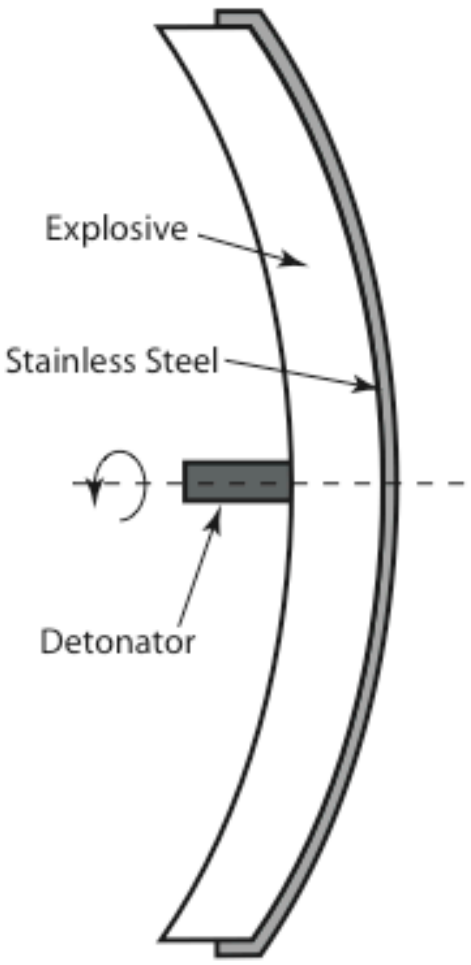


UNCLASSIFIED

Figure 2

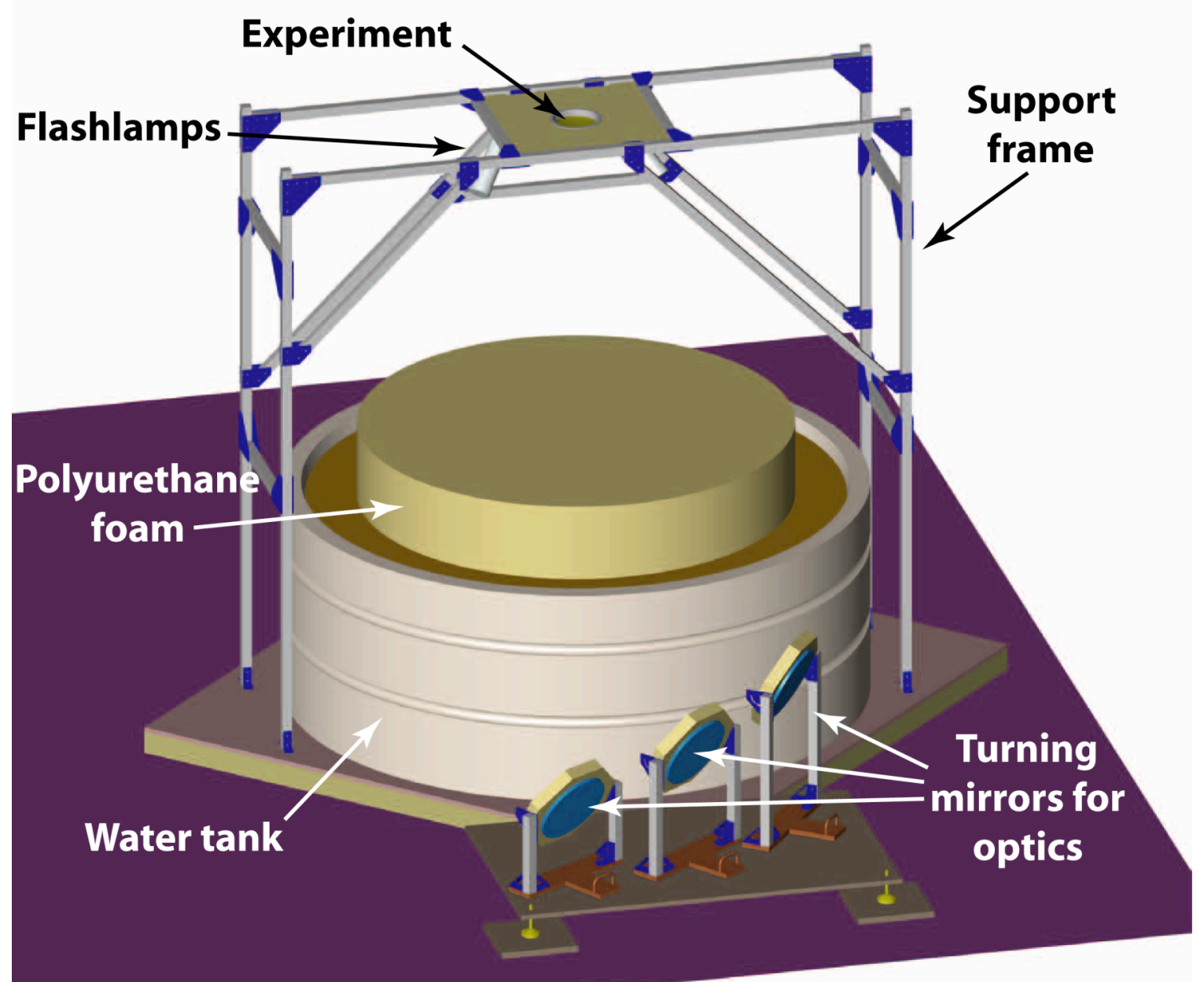




\section{UNCLASSIFIED}

Figure 3

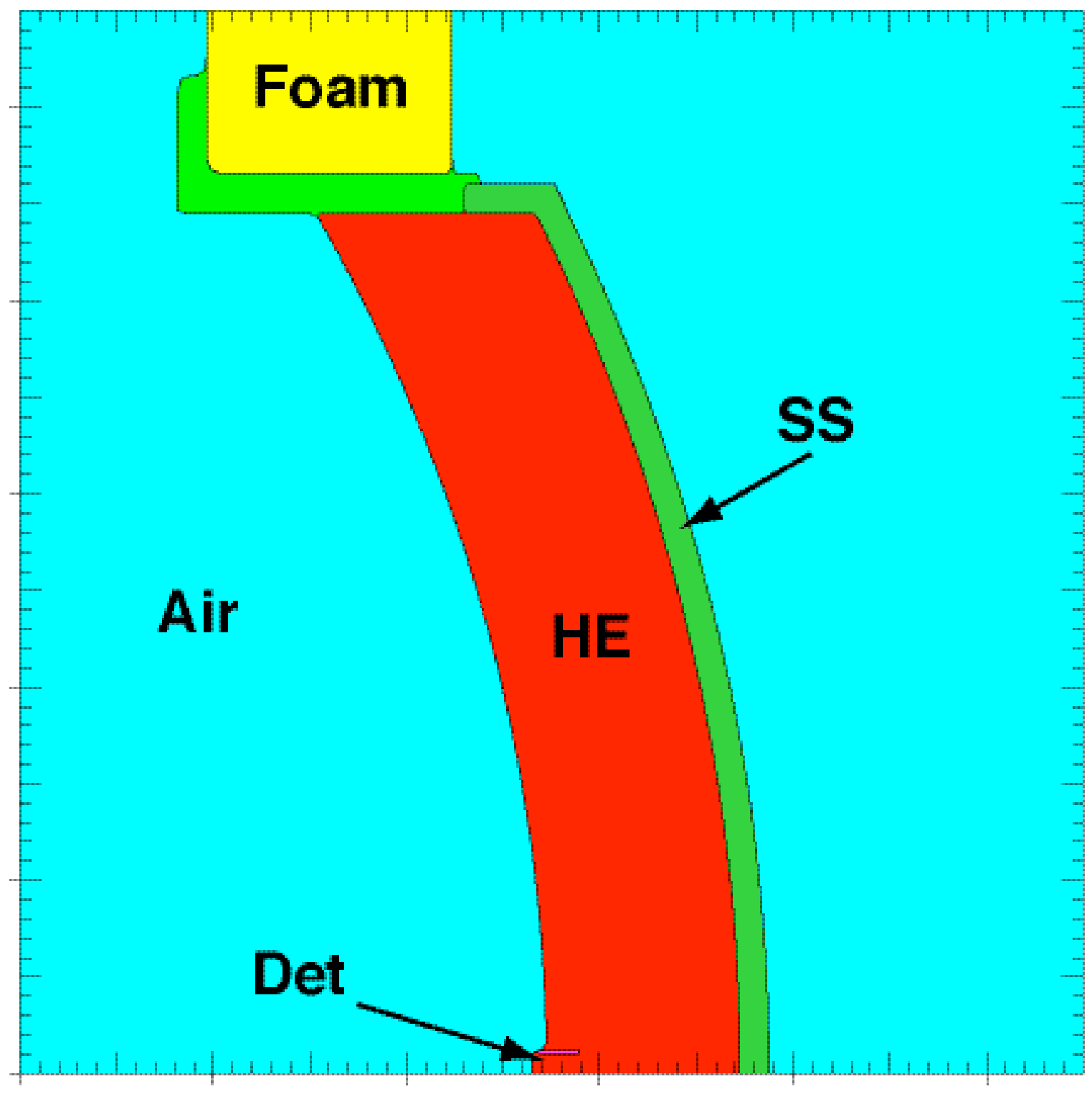


UNCLASSIFIED

\section{Figure 4}
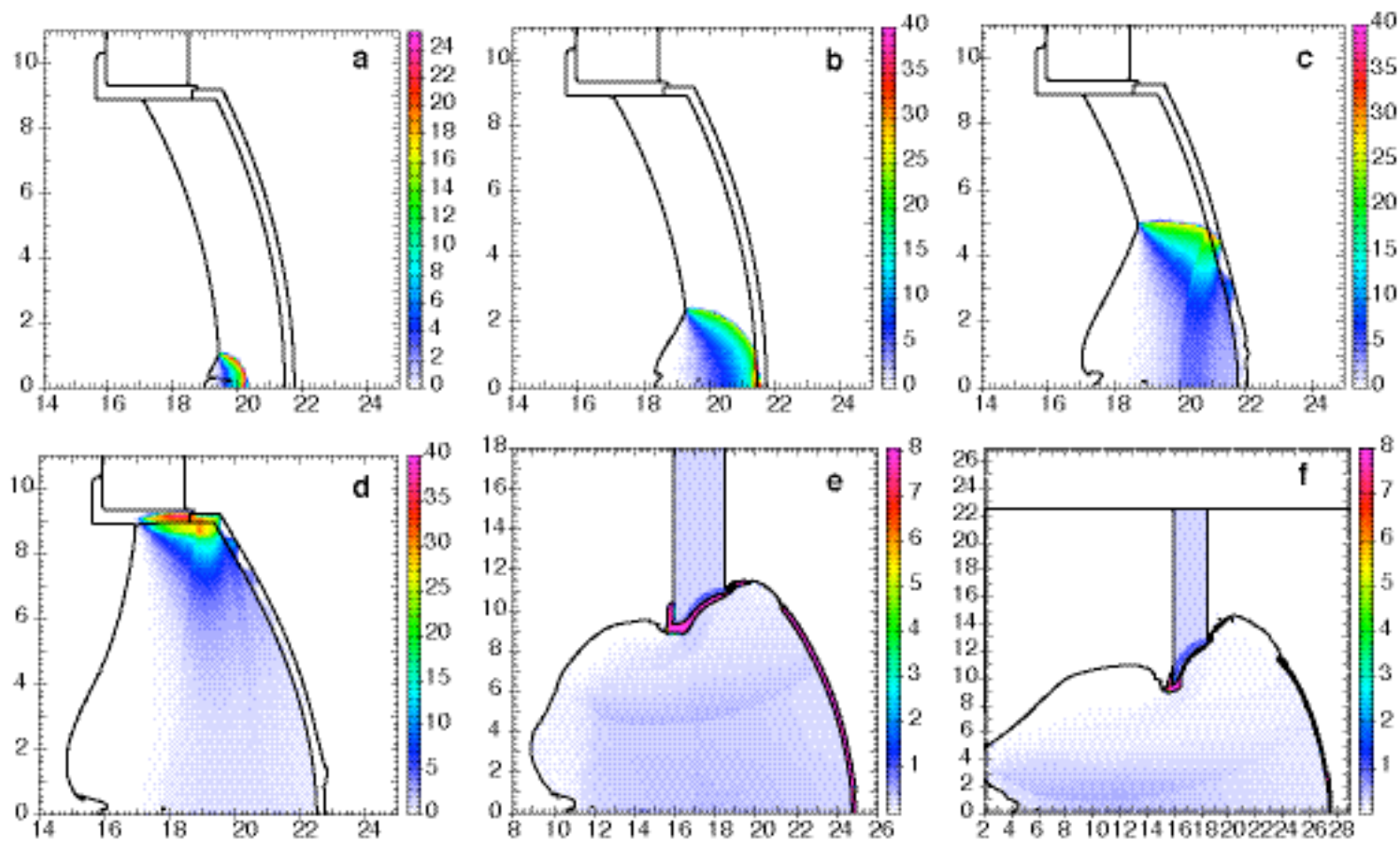


\section{UNCLASSIFIED}

Figure 5

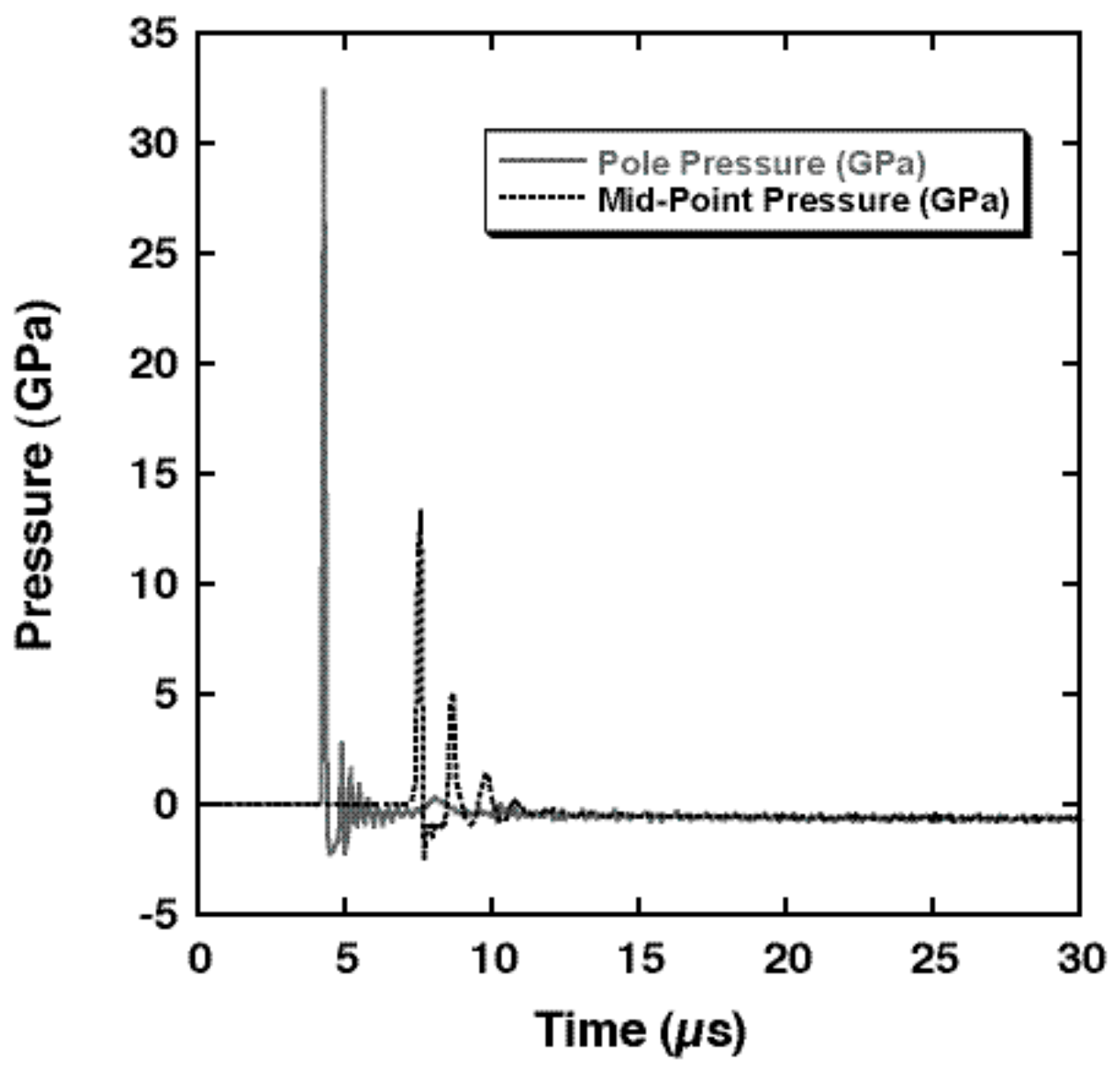


UNCLASSIFIED

Figure 6

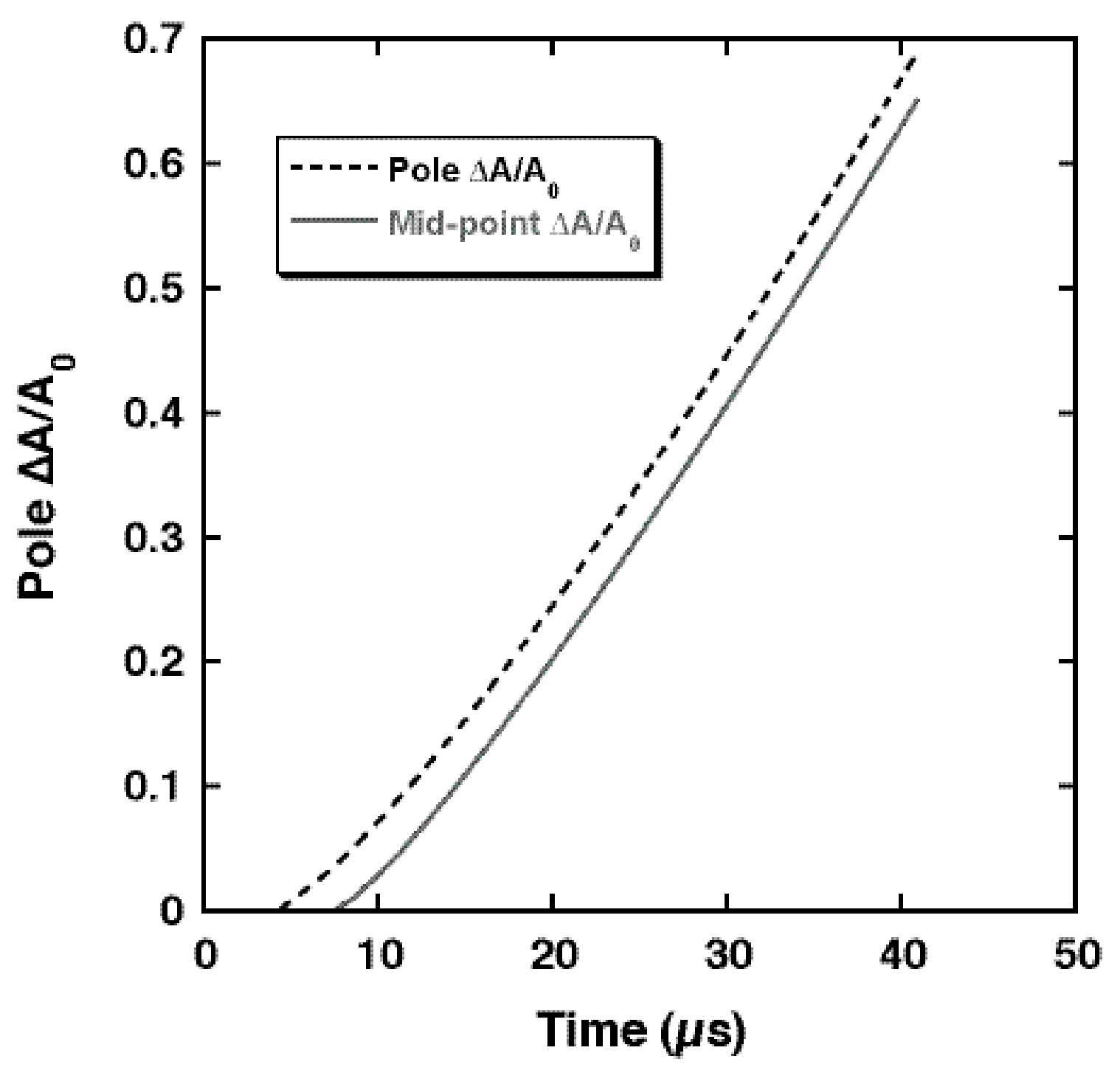


UNCLASSIFIED

Figure 7

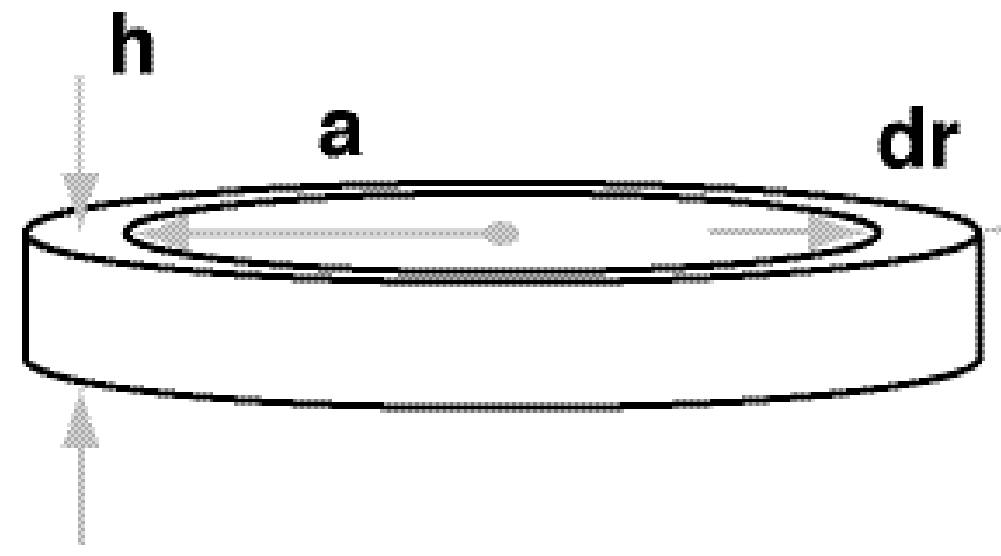




\section{UNCLASSIFIED}

Figure 8

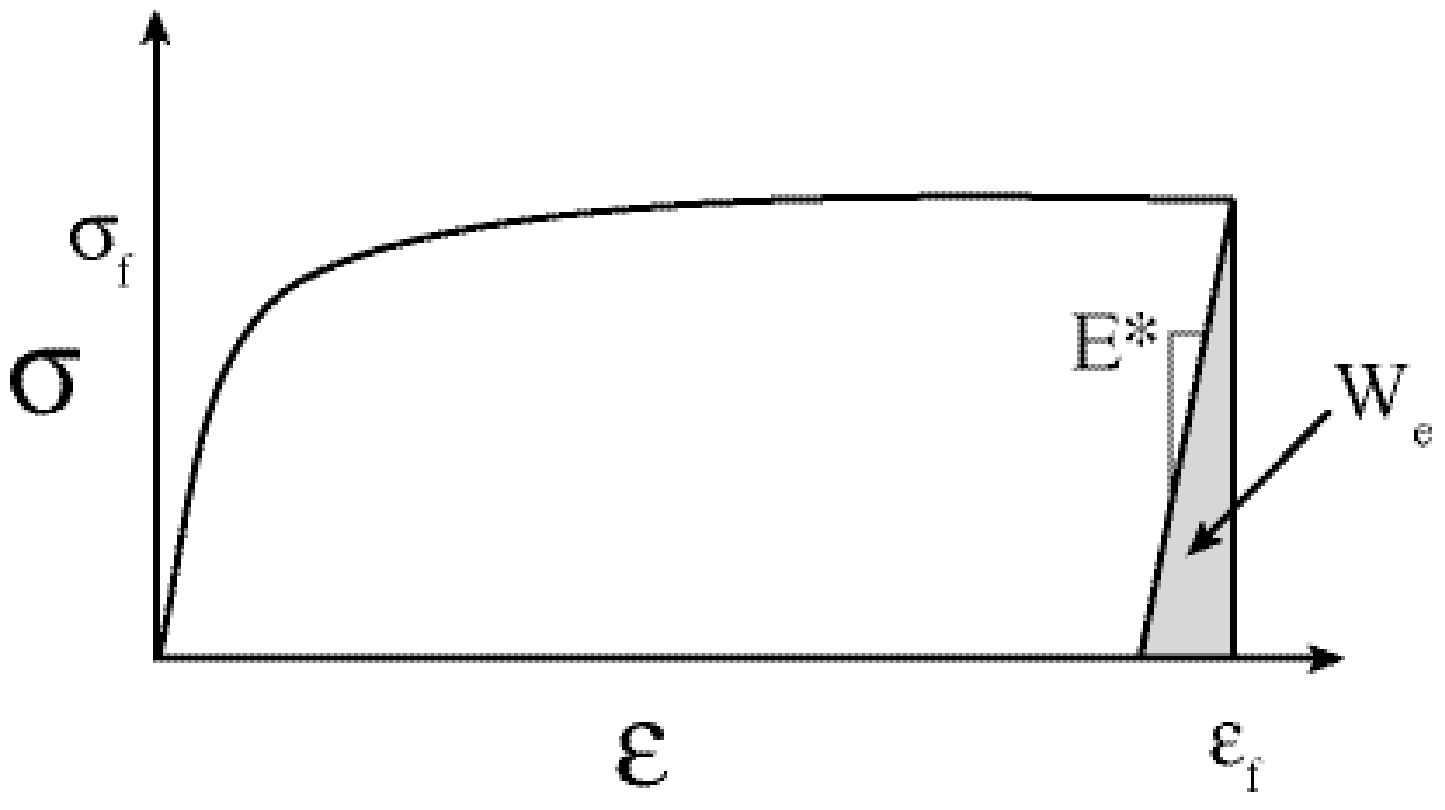




\section{UNCLASSIFIED}

Figure 9

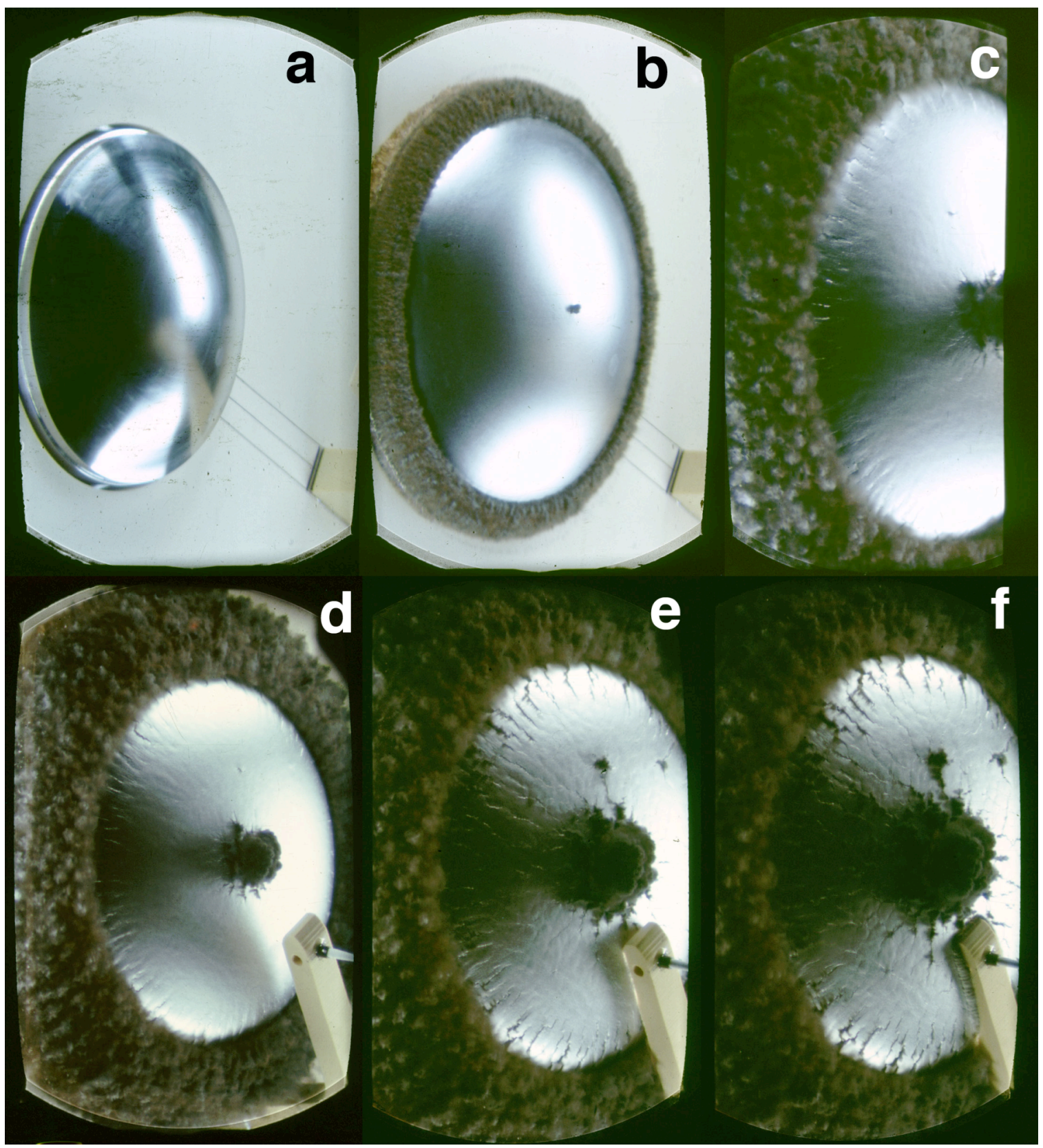


UNCLASSIFIED

Figure 10

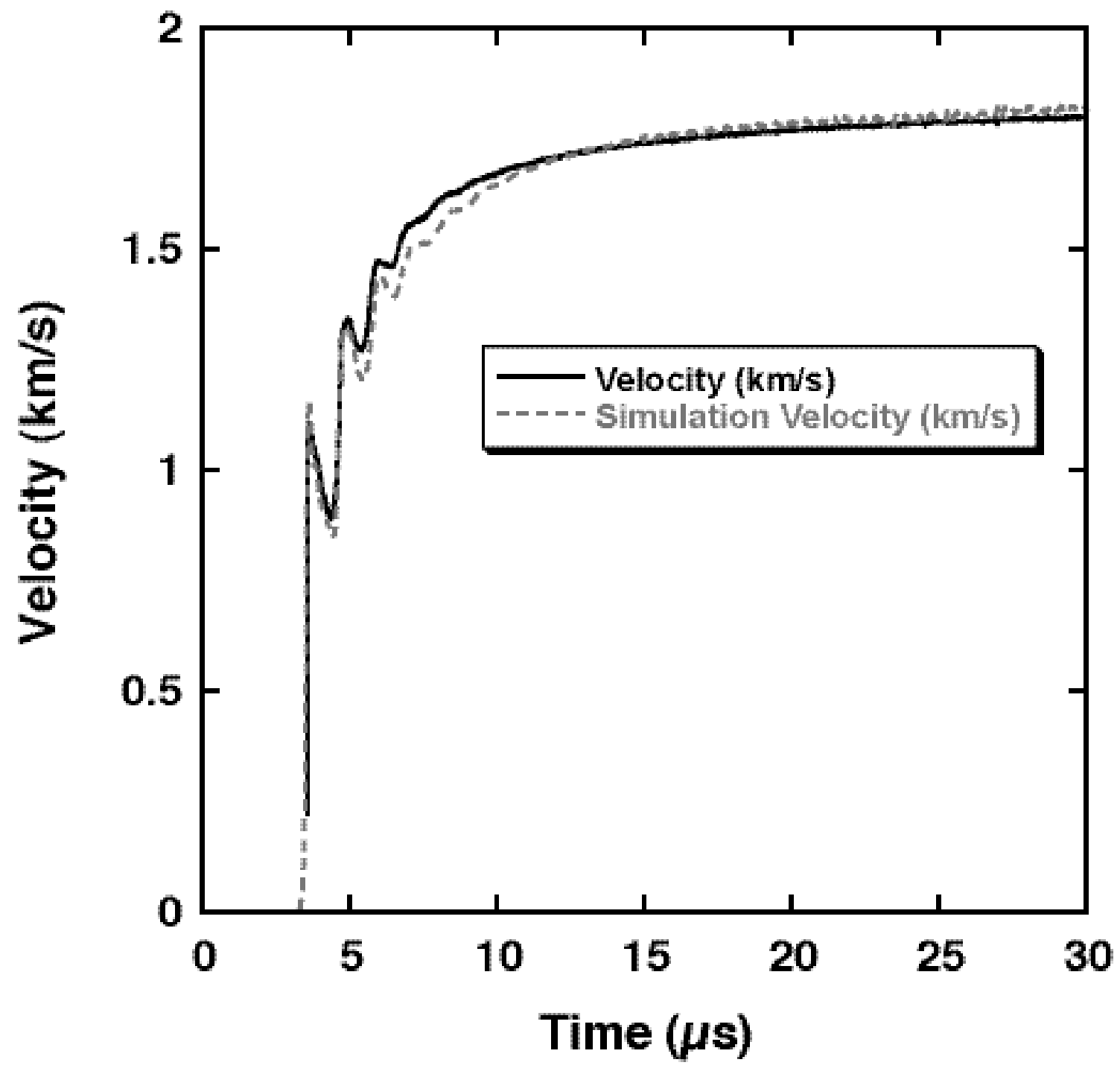


UNCLASSIFIED

Figure 11

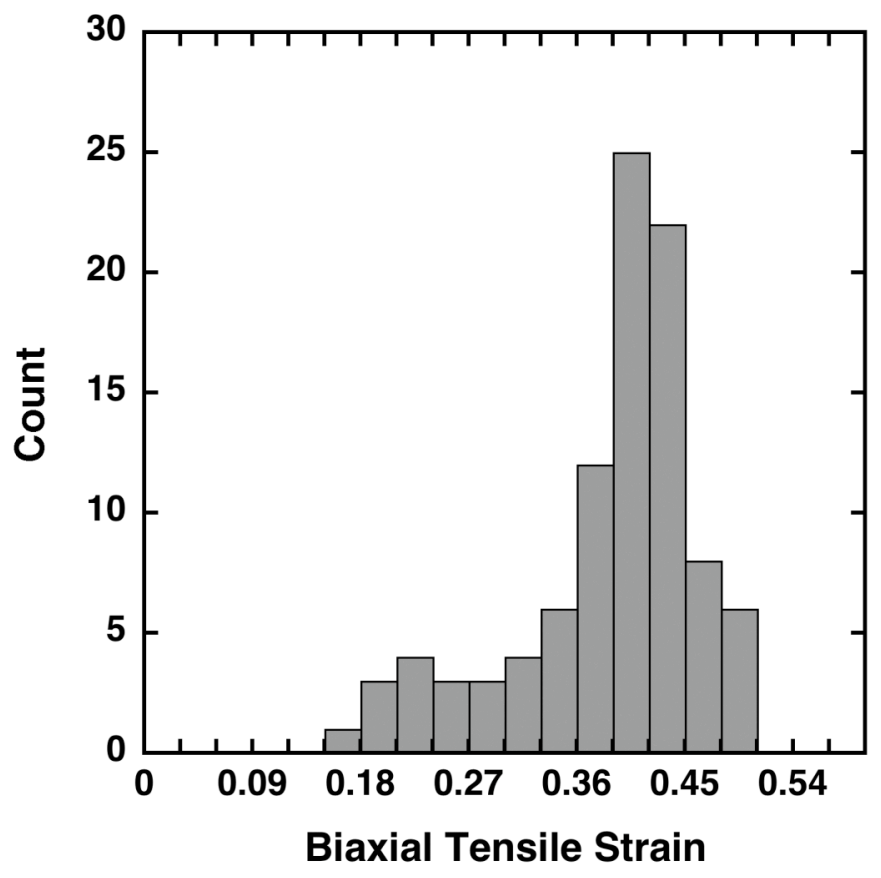




\section{UNCLASSIFIED}

Figure 12

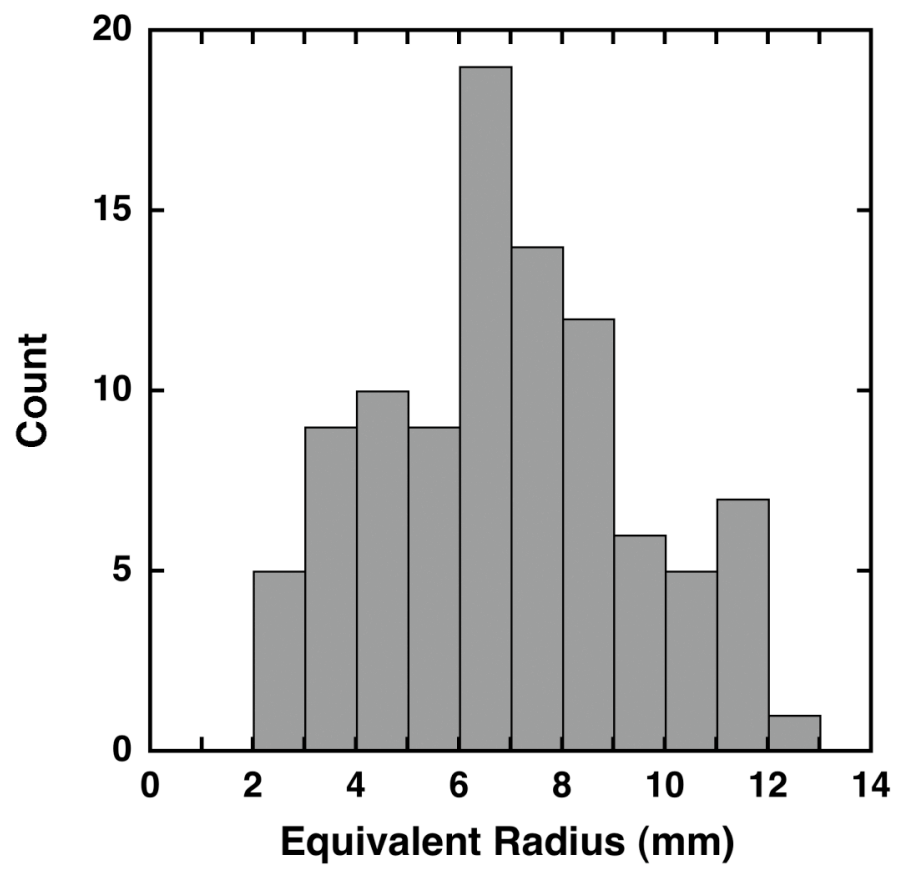


UNCLASSIFIED

Figure 13

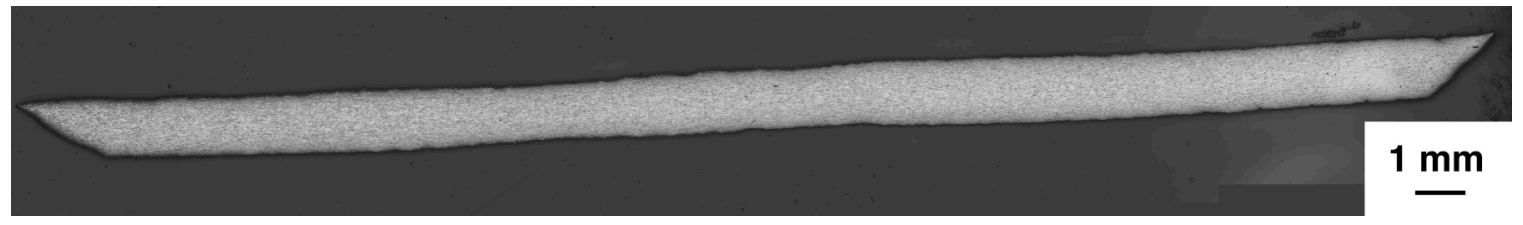


UNCLASSIFIED

Figure 14

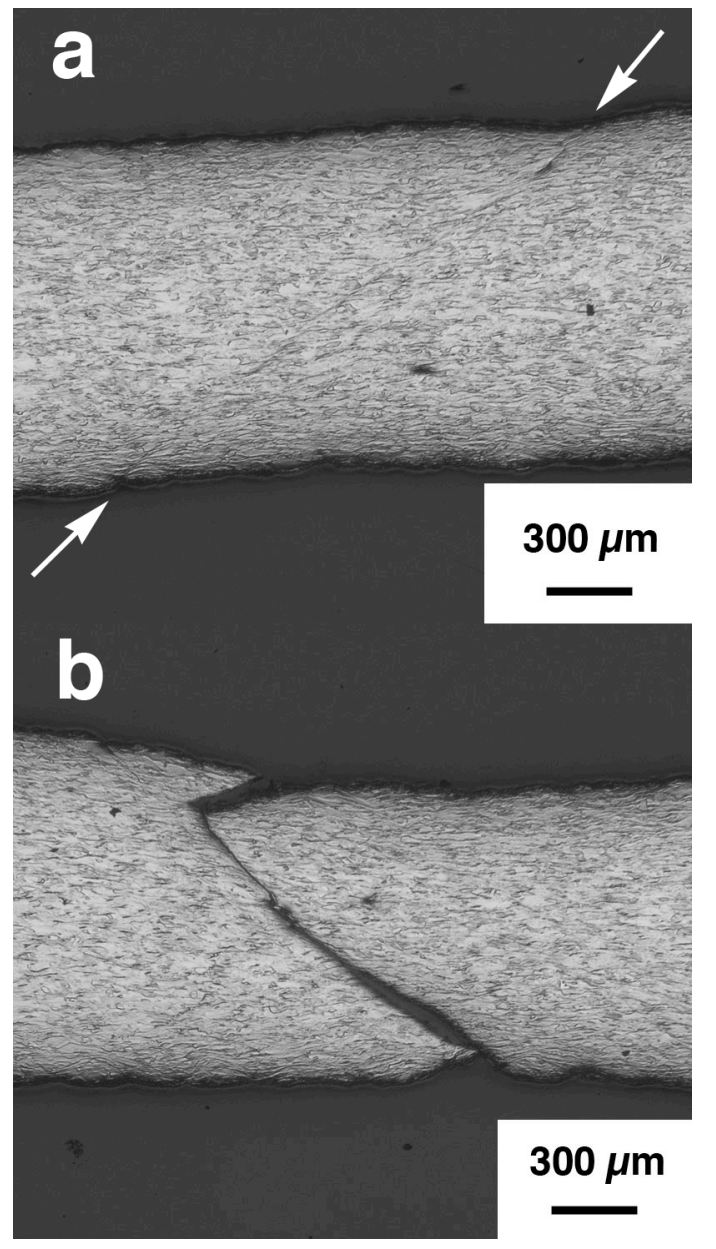


UNCLASSIFIED

Figure 15

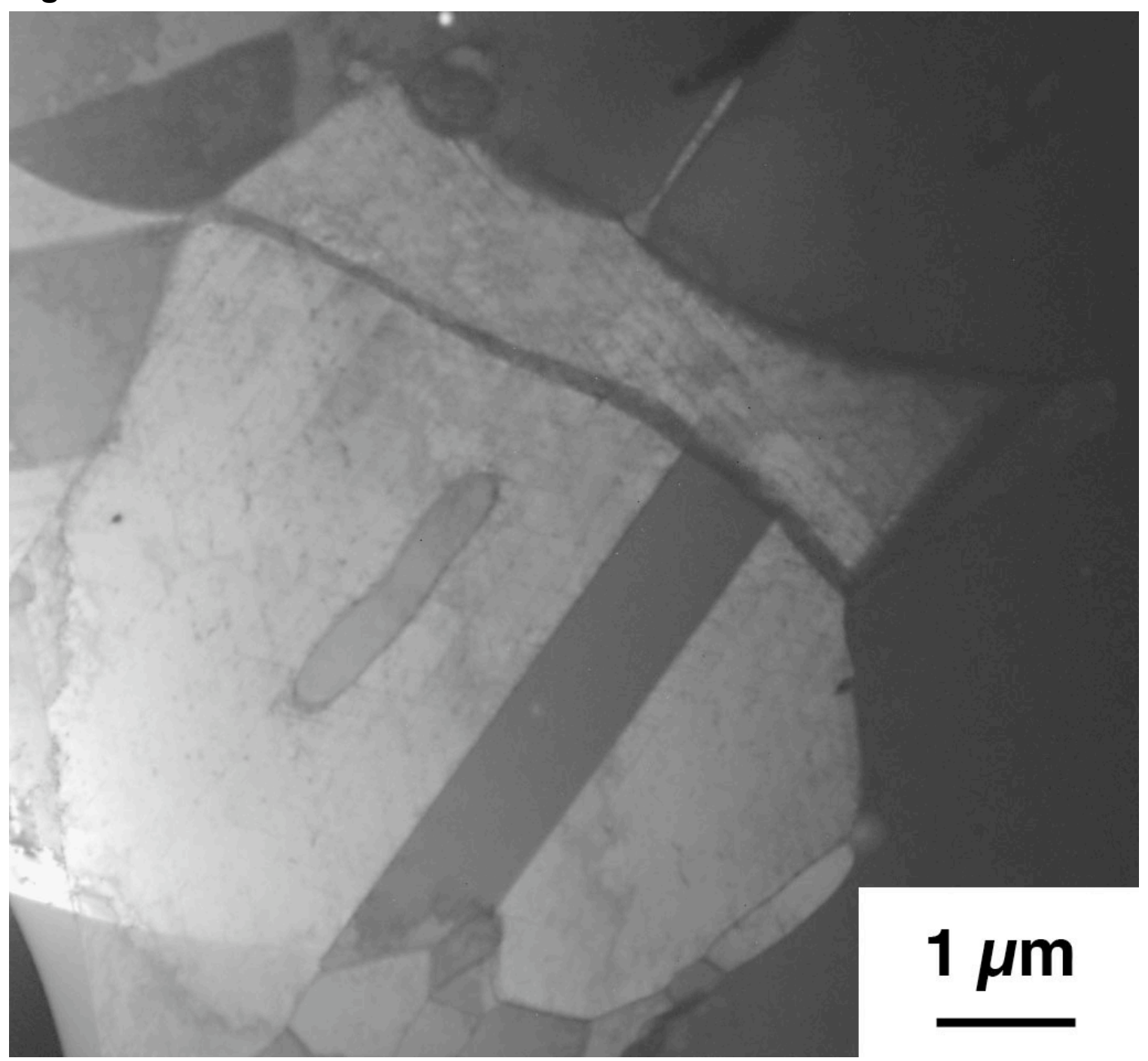




\section{UNCLASSIFIED}

Figure 16

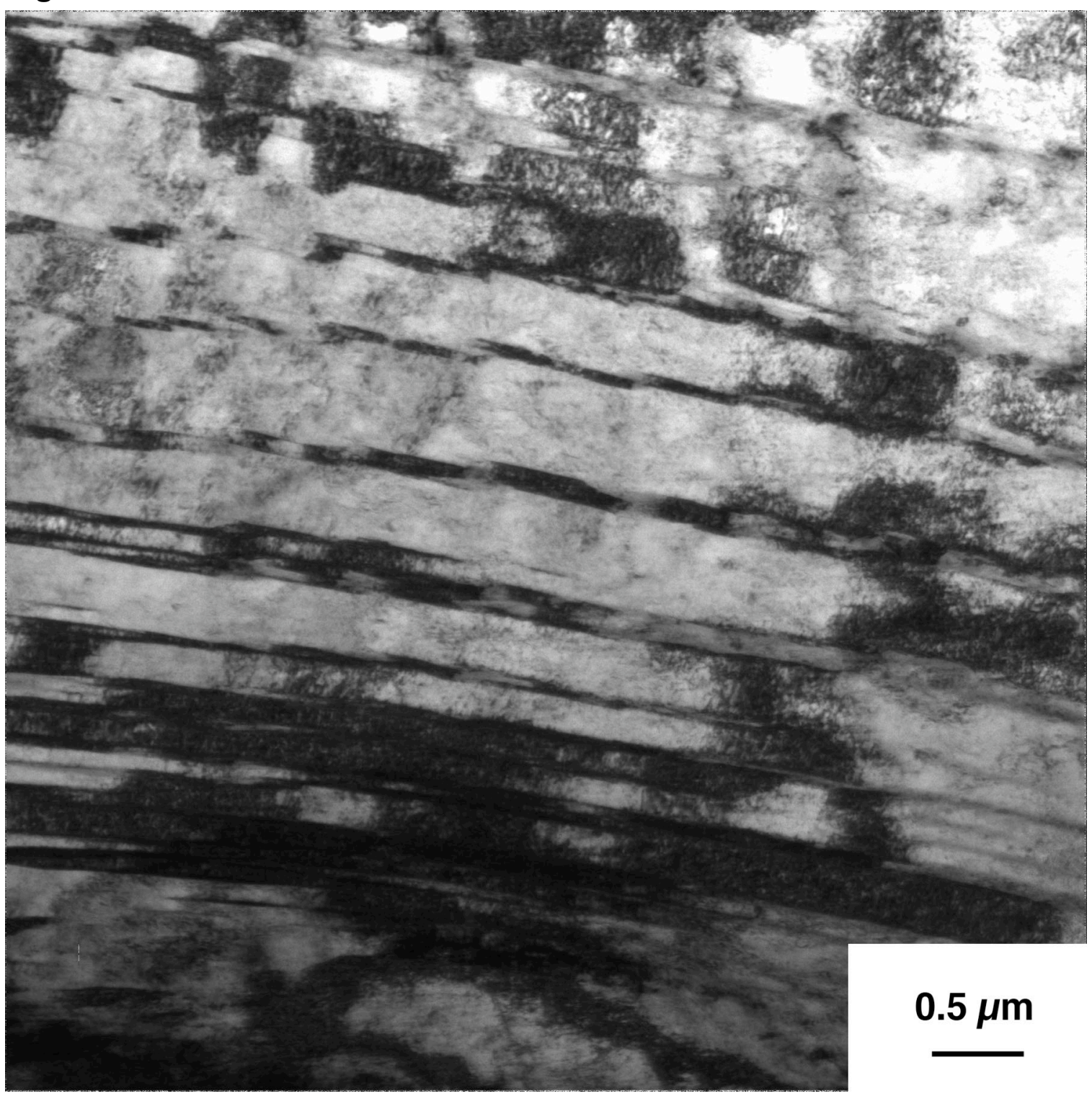




\section{UNCLASSIFIED}

\section{Figure 17}

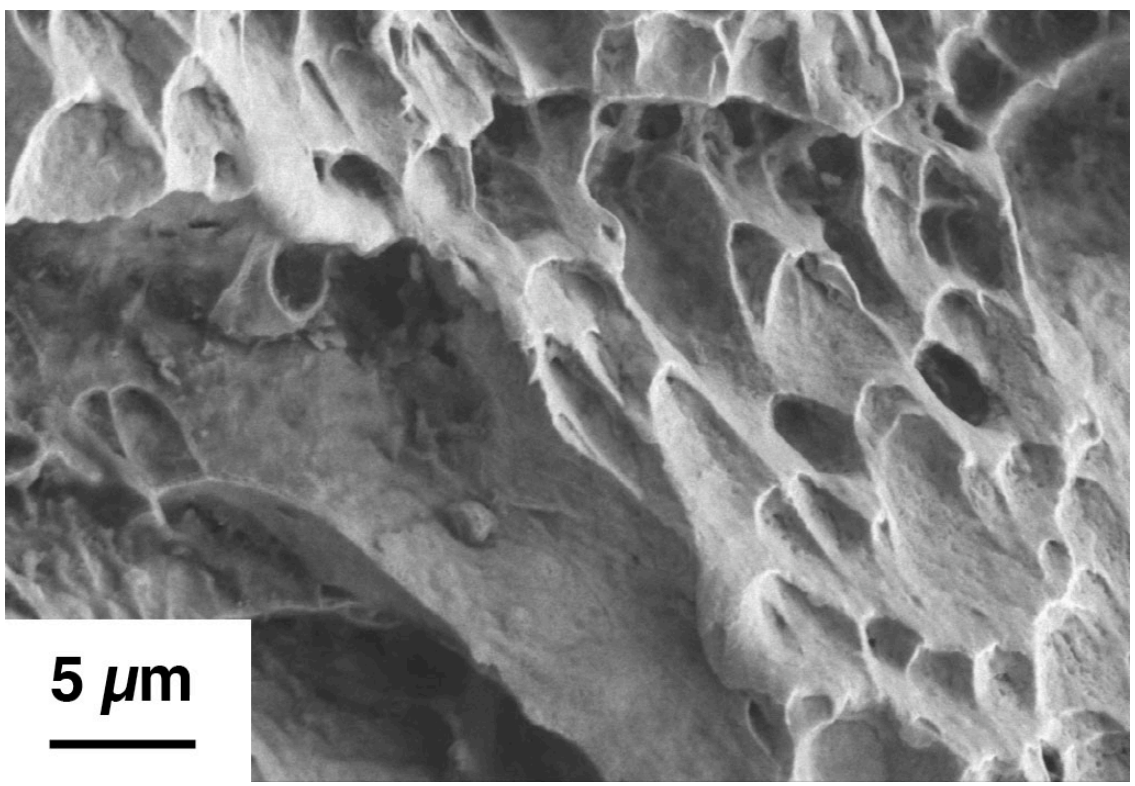

